\title{
Food security among individuals experiencing homelessness and mental illness in the At Home/Chez Soi Trial
}

\author{
Patricia O'Campo ${ }^{1,2, *}$, Stephen W Hwang ${ }^{1,3}$, Agnes Gozdzik ${ }^{1}$, Andrée Schuler ${ }^{1}$, \\ Vered Kaufman-Shriqui ${ }^{1,4}$, Daniel Poremski ${ }^{1}$, Luis Ivan Palma Lazgare ${ }^{1}$, Jino Distasio ${ }^{5}$, \\ Slimane Belbraouet ${ }^{6}$ and Sindi Addorisio ${ }^{7}$ \\ ${ }^{1}$ Centre for Research on Inner City Health, St. Michael's Hospital, 30 Bond Street, Toronto, Ontario, Canada, M5B \\ 1W8: ${ }^{2}$ Dalla Lana School of Public Health, University of Toronto, Toronto, Ontario, Canada: ${ }^{3}$ Division of General \\ Internal Medicine, Department of Medicine, University of Toronto, Toronto, Ontario, Canada: ${ }^{4}$ Department of \\ Nutritional Sciences, Ariel University, Ariel, Israel: ${ }^{5}$ Department of Geography \& Institute of Urban Studies, University \\ of Winnipeg, Winnipeg, Manitoba, Canada: ${ }^{6}$ School of Food Science, Nutrition and Family Studies, University of \\ Moncton, Moncton, New Brunswick, Canada: ${ }^{7}$ Centre for Health Evaluation and Outcomes Sciences (CHEOS), \\ Vancouver, British Columbia, Canada
}

Submitted 18 February 2016: Final revision received 5 February 2017: Accepted 20 February 2017: First published online 31 May 2017

\begin{abstract}
Objective: Individuals experiencing homelessness are particularly vulnerable to food insecurity. The At Home/Chez Soi study provides a unique opportunity to first examine baseline levels of food security among homeless individuals with mental illness and second to evaluate the effect of a Housing First (HF) intervention on food security in this population.

Design: At Home/Chez Soi was a 2-year randomized controlled trial comparing the effectiveness of HF compared with usual care among homeless adults with mental illness, stratified by level of need for mental health services (high or moderate). Logistic regressions tested baseline associations between food security (US Food Security Survey Module), study site, sociodemographic variables, duration of homelessness, alcohol/substance use, physical health and service utilization. Negative binomial regression determined the impact of the HF intervention on achieving levels of high or marginal food security over an 18-month follow-up period (6 to 24 months).

Setting: Community settings at five Canadian sites (Moncton, Montreal, Toronto, Winnipeg and Vancouver).

Subjects: Homeless adults with mental illness ( $n$ 2148).

Results: Approximately $41 \%$ of our sample reported high or marginal food security at baseline, but this figure varied with gender, age, mental health issues and substance use problems. High need participants who received HF were more likely to achieve marginal or high food security than those receiving usual care, but only at the Toronto and Moncton sites.

Conclusions: Our large multi-site study demonstrated low levels of food security among homeless experiencing mental illness. HF showed promise for improving food security among participants with high levels of need for mental health services, with notable site differences.
\end{abstract}

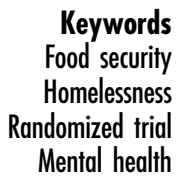

Keywords

Food security Randomized trial Mental health
Food security is an ideal state when people at all times have access to sufficient, safe and nutritious food to remain healthy and active ${ }^{(1,2)}$. Food insecurity occurs when access to food is limited, inadequate or insecure to meet the dietary requirements for a productive and healthy life of individuals, families or households ${ }^{(1)}$. Food insecurity, with its associated health consequences, remains pervasive in Canada ${ }^{(3-7)}$. In 2012-2013, 13-14\% of North American households were food insecure ${ }^{(8,9)}$, with acute or chronic financial insecurity or poverty as the main determinant of household food insecurity ${ }^{(10-12)}$.

People experiencing poverty and homelessness are at heightened risk of experiencing hunger and food insecurity $^{(13)}$. A national survey of individuals experiencing homelessness in the USA found that approximately $40 \%$ of participants reported fasting for an entire day in the past month or were unable to afford food in the past month, while $12 \%$ engaged in subsistence eating 
(eating out of trash cans or via hand-outs) in the last week $^{(13)}$. In the same study, approximately three-fifths of the respondents also reported food inadequacy in terms of quantity or preference (61\%) and infrequent meals $(57 \%)^{(13)}$. In Toronto, Canada, Holland et al. reported that $72 \%$ of individuals experiencing homelessness were food insecure; specifically, $30 \%$ of the sample reported marginal levels of food security, $10 \%$ low food security and $32 \%$ very low food security ${ }^{(14)}$. A series of studies of youths experiencing homelessness in Toronto similarly demonstrated that this sub-population experiences nutritional deficiencies ${ }^{(15,16)}$, severe food insecurity (among $85 \%$ of females and $73 \%$ of males) ${ }^{(17)}$ and chronic food deprivation (among $43 \%$ of females and $28 \%$ of males) ${ }^{(17)}$.

Previous research has revealed that specific individuallevel factors are associated with food security among individuals experiencing homelessness, including living at or below the poverty line, mental and physical health issues, increased rates of hospitalization and emergency department visits, and chronic homelessness ${ }^{(13,18,19)}$. Population-level factors are also associated with food security among individuals experiencing homelessness. Emergency shelter policies have been shown to constrain food choice by restricting the storage of perishable items and providing limited cooking facilities and food storage space. Such policies often lead to purchasing of nonperishable and less healthful food products ${ }^{(20,21)}$.

Although prior research has shown that up to $71 \%$ of individuals with severe mental illness experience food insecurity $^{(22-24)}$, to date, the prevalence of and factors associated with food insecurity have not been specifically examined in a sample of individuals experiencing homelessness and mental illness. We seek to add to this small but growing literature.

Interventions to improve food security among homeless people have focused primarily on charity food programmes such as food banks and soup kitchens ${ }^{(25,26)}$ and communitybased initiatives such as community kitchens and gardens ${ }^{(27,28)}$. However, studies on these topics have been plagued by low participant rates ${ }^{(7,25,29,30)}$ and the evidence of their positive impacts on reducing food insecurity is inconclusive ${ }^{(25,28,29)}$. Housing First $(\mathrm{HF})$, which combines permanent housing in conjunction with access to mental health supports, has emerged as a promising intervention for individuals experiencing homelessness and mental illness, and has been shown to be effective in improving residential stability, quality of life and health-service use ${ }^{(31-35)}$; however, the impact of HF on food security is unknown. We hypothesized that access to stable housing and mental health supports would improve food security among homeless adults experiencing mental illness. Thus the present study aimed to: (i) assess the levels and predictors of baseline food insecurity among individuals experiencing homelessness and mental illness participating in the At Home/Chez Soi study; and (ii) determine the effect of an HF intervention on food security over 18 months of follow-up.

\section{Methods}

\section{At Home/Chez Soi study design}

The At Home/Chez Soi study was a multi-site randomized controlled trial that examined the effectiveness of an $\mathrm{HF}$ intervention among adults experiencing both homelessness and mental illness across five sites in Canada ${ }^{(31,33,36)}$. HF offers individuals experiencing homelessness and mental illness permanent housing in conjunction with access to mental health support services, without the prerequisites for abstinence or treatment acceptance imposed by more traditional 'treatment first' interventions aimed at this population $^{(35)}$. Details of the research protocol have been previously published ${ }^{(36)}$. Briefly, eligibility for the At Home/Chez Soi study included: (i) legal adult age $(\geq 18$ years; $\geq 19$ years in Vancouver); (ii) absolute homelessness or being precariously housed; and (iii) severe mental illness with or without a concurrent substance use problem. Participants were excluded if they were not legally residing in Canada or were already receiving assertive community treatment (ACT) or intensive case management $(\mathrm{ICM})^{(36)}$. The study was approved by the research ethics boards of all participating institutions.

Prior to randomization, participants were classified as high or moderate need based on their need level for mental health services. High need (HN) participants were identified as having: (i) a Multnomah Community Ability Scale (MCAS) ${ }^{(37)}$ score of $\leq 62$; (ii) a Mini International Neuropsychiatric Interview 6.0 (MINI 6.0) ${ }^{(38)}$ diagnosis of current psychotic or bipolar disorder (or an observation of psychotic behaviour); and (iii) one of the following criteria: $\geq 2$ hospitalizations for mental illness in any one of the past 5 years, co-morbid substance use or recent arrest/ incarceration. Moderate need (MN) participants were identified as all others who met eligibility criteria but were not identified as HN. People with HN for mental health services are best served by a multidisciplinary ACT team, which provides comprehensive $24 \mathrm{~h} / \mathrm{d}$ mental health and crisis services. ICM provides a lower intensity of mental health services for people who do not require ACT: case managers work one-on-one with the client to assess his or her needs and secure necessary services from communitybased providers. As a result, participants in the HN group were randomized to $\mathrm{HF}$ and ACT or a standard-care treatment as usual (TAU) group, while those in the MN group were randomized to HF and ICM or TAU. In Moncton, both $\mathrm{MN}$ and $\mathrm{HN}$ participants were randomized to HF and ACT or TAU. The protocol also included the addition of site-specific intervention arms that have been adapted to the local context (see Fig. 1 for flow diagram).

Participants randomized to the HF intervention were provided with housing in areas of the city they preferred. To help facilitate participant community integration, housing was scattered in units throughout the city ('scattered-site') and a maximum of $20 \%$ of the total units in any one building or residence were dedicated to study 


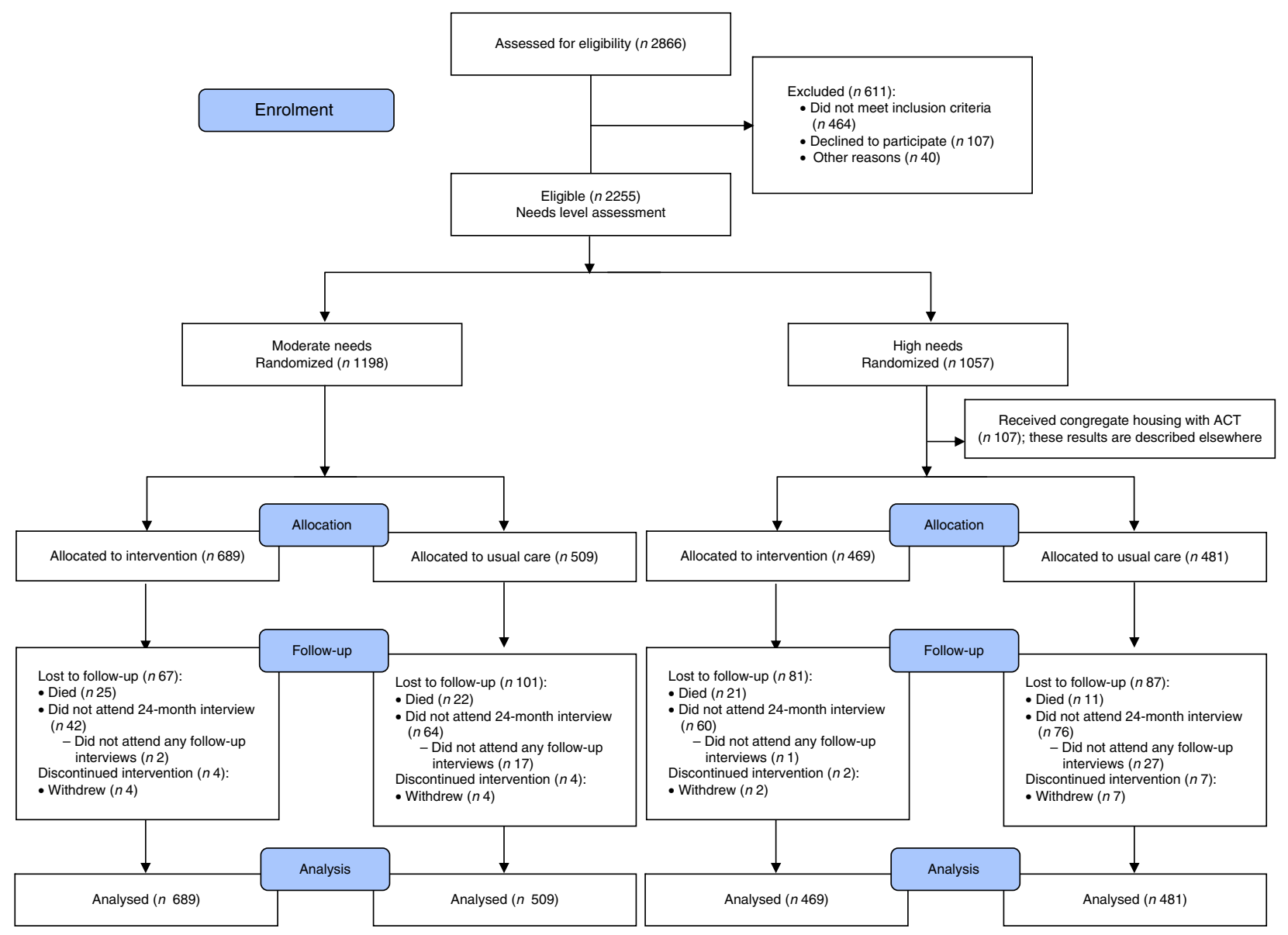

Fig. 1 Participant flow diagram (ACT, assertive community treatment)

participants ${ }^{(36)}$. In addition to housing, intervention participants also received mental health services offered via either ICM or ACT, which were provided off-site and not tied to their tenancy. TAU participants were provided with a list of existing resources in their city, which they could access at their choosing. Sites varied in the number and extent of services available; however, some access to food banks and emergency shelters and drop-in centres that offered meals was available at all sites and available to participants in both randomization groups. All participants were followed for 2 years post-randomization.

\section{Participants}

The sample consisted of 2148 individuals experiencing homelessness and mental illness who were enrolled in the At Home/Chez Soi study from October 2009 to July 2011. All participants provided written informed consent and received an honorarium, ranging from $\$ C A N 10$ to $\$ C A N 80$, depending on the site and interview duration, for their participation in the study.

\section{Data collection}

Participants completed interviews at study entry and subsequently every 3 months during the 24-month period following enrolment. All study interviews were conducted by trained interviewers who input the data directly into a secure online database. In addition to food security, the survey assessed sociodemographic characteristics, healthservice use, housing situation, community functioning, physical and mental health status and substance use, which have been described in detail in a former publication ${ }^{(36)}$.

\section{Variables}

Food security status, the main outcome, was assessed every 6 months, using a modified version of the US Food Security Survey Module (US FSSM) ${ }^{(39)}$ for single adults, with the period of interest spanning the $30 \mathrm{~d}$ prior to the interview. This instrument, previously tested in a sample of individuals who were homeless, has shown moderate agreement with the original version of the US FSSM and was preferred over the original US FSSM instrument as being more relevant to homeless people ${ }^{(14)}$. It is important to note that while frequently used as a measure of food security, the US FSSM measures food security as resulting directly from constraints of financial resources. As a result, it does not encompass the multifaceted dimensions of food security ${ }^{(39)}$, which are captured by the FAO's definition and include 'physical, social and economic access to sufficient, safe and nutritious food which meets their dietary needs and food preferences for an active and 
Table 1 Old and new categories of food security from the US Food Security Survey Module (US FSSM) ${ }^{(41)}$

\begin{tabular}{llll}
\hline $\begin{array}{l}\text { US FSSM } \\
\text { score }\end{array}$ & Old category label & New category label & Definition \\
\hline 0 & $\begin{array}{l}\text { Food security } \\
\text { Food insecurity without } \\
\text { hunger }\end{array}$ & $\begin{array}{c}\text { High food security } \\
\text { Marginal food } \\
\text { security }\end{array}$ & $\begin{array}{c}\text { No reported indications of food access problems or limitations } \\
\text { One or two reported indications of food insecurity, typically relating to } \\
\text { anxiety over adequate food or shortage of food in the house. Little } \\
\text { or no indication of changes in diets or food intake }\end{array}$ \\
$\begin{array}{c}\text { Food insecurity with hunger } \\
\text { (moderate) }\end{array}$ & $\begin{array}{c}\text { Low food security } \\
\text { indication of reduced food intake }\end{array}$ & $\begin{array}{c}\text { Reports of multiple indications of disrupted eating patterns and } \\
\text { reduced food intake }\end{array}$ \\
$6-10$ & $\begin{array}{c}\text { Food insecurity with hunger } \\
\text { (severe) }\end{array}$ & $\begin{array}{c}\text { Very low food } \\
\text { security }\end{array}$ & \\
\hline
\end{tabular}

healthy life ${ }^{,(2,40)}$. The resulting total scores for the US FSSM scale range from 0 to 10 and are classified into four food security status groups: (i) high (score of 0); (ii) marginal (score of 1 or 2); (iii) low (score of 3-5); (iv) and very low (score of 6-10). These updated categories were outlined by the US Department of Agriculture in 2006, based on recommendations from the Committee on National Statistics (Table 1) ${ }^{(41)}$. Prior to these recommendations, a score of 0 was defined as 'food secure', while a score of 1 or 2 was 'food insecure without hunger', 3-5 was 'food insecure with hunger (moderate)' and 6-10 was 'food insecure with hunger (severe)'. Since 2006, the updated labels interpret all categories in terms of level of food security (very low to high). According to the US FSSM guide, the combination of the first two categories (high and marginal food security) can continue to be considered 'food secure' while the latter two categories (low and very food security) can be considered 'food insecure, ${ }^{\text {(41) }}$.

Other variables used in our analyses included the $\mathrm{MCAS}^{(37)}$ to assess community functioning and the Colorado Symptom Index $(\mathrm{CSI})^{(42)}$ to assess psychiatric symptom severity. For the CSI, we created a dichotomous variable $(<30 v$. $\geq 30)$, as prior research indicates that scores higher than 30 can be used to predict a psychiatric diagnosis $^{(42)}$. Two variables assessed drug or alcohol problems among participants: the number of days in the past $30 \mathrm{~d}$ in which alcohol or drug problems were experienced and the percentage of income spent on alcohol or non-prescription drugs. Four self-reported physical health conditions were included based on their hypothesized association with food intake: ulcers, bowel problems, high blood pressure and diabetes. Information about service use was included, specifically whether the participant had seen a health or social services provider at his or her office in the past month and any emergency room visits in the past 6 months. Demographic characteristics including age, sex, study site and duration of homelessness (dichotomized as $<3$ years $v . \geq 3$ years) were also included.

\section{Statistical analysis}

Descriptive statistics were first generated and stratified by level of need for mental health services. We then used logistic regression models to determine associations between high or marginal levels of food security status and several sociodemographic covariates for participants at study enrolment. We included variables that were selected a priori to be potentially associated with food security: age, sex, duration of homelessness, MCAS, CSI, days experienced drug/alcohol problems, percentage of income spent on alcohol/drugs, physical health problems and service use.

To determine the impact of the HF intervention on food security, negative binomial regression models were used due to overdispersed count data for the number of times participants achieved 'food security' (either high or marginal food security on the US FSSM) ${ }^{(41)}$ between 6 and 24 months after randomization. For assessment of change in food security, we excluded baseline data, as the enrolment observation points would not reflect the impact of the intervention. To retain our large sample size, we took a conservative approach and assigned values of 'food insecurity' (either low or very low food security on the US FSSM) to participants with missing US FSSM data. We used descriptive statistics to test if any baseline variables differed between participants with complete US FSSM data and those with missing data; variables that differed significantly between the groups were included as covariates in the negative binomial regression models.

Models tested the main effects of treatment group and study site as well as an interaction between treatment group and study site. The model estimates the rate ratios and $95 \%$ confidence intervals for counts of the number of times participants achieved high or marginal food security on the US FSSM between 6 and 24 months. All statistical analyses were performed using the statistical software package SAS version 9.4. A two-tailed test was used and a $P$ value $<0.05$ was considered statistically significant ${ }^{(43)}$.

\section{Results}

Baseline characteristics of study participants are shown in Table 2. We obtained information about baseline food security status for 2097 participants, 914 and 1183 from the $\mathrm{HN}$ and MN groups, respectively. Interestingly, fewer HN participants had marginal or high food security ( $n 347$, $38 \%$ ) compared with MN participants ( $n$ 517, 44\%). 
Table 2 Characteristics of At Home/Chez Soi study participants at enrolment for all five sites by study arm. Participants were individuals ( $n 2148$ ) experiencing homelessness and mental illness enrolled at five Canadian sites (Moncton, Montreal, Toronto, Winnipeg and Vancouver), October 2009 to July 2011

\begin{tabular}{|c|c|c|c|c|c|c|c|c|c|c|}
\hline \multirow[b]{3}{*}{ Characteristics } & \multicolumn{5}{|c|}{$\mathrm{MN}(n$ 1198) } & \multicolumn{5}{|c|}{$\mathrm{HN}(n 950)$} \\
\hline & \multicolumn{2}{|c|}{$\mathrm{HF}(n 689)$} & \multicolumn{3}{|c|}{ TAU $(n 509)$} & \multicolumn{2}{|c|}{$\mathrm{HF}(n$ 469) } & \multicolumn{3}{|c|}{ TAU $(n$ 481) } \\
\hline & $n$ or mean & $\%$ or SD & $n$ or mean & $\%$ or SD & $P$ & $n$ or mean & $\%$ or SD & $n$ or mean & $\%$ or SD & $P$ \\
\hline \multicolumn{11}{|l|}{ Demographic variables } \\
\hline Age (years) & & & & & 0.92 & & & & & 0.22 \\
\hline 18 to $<25$ & 57 & $8 \cdot 3$ & 45 & $8 \cdot 8$ & & 56 & 11.9 & 46 & $9 \cdot 6$ & \\
\hline 25 to $<35$ & 140 & $20 \cdot 3$ & 100 & $19 \cdot 7$ & & 132 & $28 \cdot 1$ & 130 & $27 \cdot 0$ & \\
\hline 35 to $<45$ & 179 & $26 \cdot 0$ & 136 & $26 \cdot 7$ & & 128 & $27 \cdot 3$ & 141 & $29 \cdot 3$ & \\
\hline 45 to $<55$ & 235 & $34 \cdot 1$ & 164 & $32 \cdot 2$ & & 126 & $26 \cdot 9$ & 120 & $25 \cdot 0$ & \\
\hline $55+$ & 78 & 11.3 & 78 & $12 \cdot 6$ & & 27 & $5 \cdot 8$ & 44 & 9.2 & \\
\hline Male & 449 & $65 \cdot 2$ & 346 & 68.0 & 0.31 & 320 & 68.2 & 329 & 68.4 & 0.72 \\
\hline Total income last month ( $\$ \mathrm{CAN})$, mean and SD & $644 \cdot 81$ & $505 \cdot 37$ & $704 \cdot 66$ & $718 \cdot 70$ & 0.63 & $733 \cdot 54$ & $814 \cdot 25$ & $649 \cdot 38$ & $604 \cdot 59$ & 0.25 \\
\hline $\begin{array}{l}\text { Site } \\
\text { Moncton }\end{array}$ & - & & - & & $<0.01$ & 101 & 21.5 & 100 & $20 \cdot 8$ & 0.98 \\
\hline Montreal & 204 & $29 \cdot 6$ & 102 & $20 \cdot 0$ & & 81 & $17 \cdot 3$ & 82 & $17 \cdot 1$ & \\
\hline Toronto & 204 & $29 \cdot 6$ & 174 & $34 \cdot 2$ & & 97 & $20 \cdot 7$ & 100 & $20 \cdot 8$ & \\
\hline Winnipeg & 181 & $26 \cdot 3$ & 133 & $26 \cdot 1$ & & 100 & $21 \cdot 3$ & 99 & $20 \cdot 6$ & \\
\hline Vancouver & 100 & 14.5 & 100 & $19 \cdot 7$ & & 90 & $19 \cdot 2$ & 100 & $20 \cdot 8$ & \\
\hline \multicolumn{11}{|l|}{ Homelessness } \\
\hline Lifetime duration of homelessness (years), mean and SD & 4.6 & $5 \cdot 6$ & 4.4 & $5 \cdot 1$ & 0.89 & $5 \cdot 3$ & $6 \cdot 1$ & $5 \cdot 0$ & 5.9 & 0.41 \\
\hline Lifetime duration of homelessness $\geq 3$ years & 326 & 48.4 & 237 & $47 \cdot 4$ & 0.74 & 241 & $54 \cdot 8$ & 231 & $51 \cdot 8$ & 0.37 \\
\hline \multicolumn{11}{|l|}{ Community functioning } \\
\hline MCAS total score, mean and SD & $64 \cdot 7$ & $6 \cdot 2$ & 64.7 & $6 \cdot 1$ & 0.91 & 54.8 & $7 \cdot 2$ & 54.5 & $7 \cdot 1$ & 0.58 \\
\hline \multicolumn{11}{|l|}{ Mental health and substance use } \\
\hline CSI total score $\geq 30$ & 500 & 79.4 & 364 & $80 \cdot 2$ & 0.74 & 285 & $76 \cdot 6$ & 328 & $80 \cdot 4$ & 0.20 \\
\hline Days in the past month experienced alcohol problems, mean and SD & 5.5 & $10 \cdot 4$ & 4.8 & 9.42 & 0.64 & $5 \cdot 6$ & $10 \cdot 7$ & 5.9 & $10 \cdot 5$ & 0.58 \\
\hline Days in the past month experienced drug problems, mean and SD & $6 \cdot 8$ & $11 \cdot 2$ & $6 \cdot 1$ & $10 \cdot 7$ & 0.89 & 8.1 & $12 \cdot 2$ & $8 \cdot 1$ & $12 \cdot 1$ & 0.81 \\
\hline $\begin{array}{l}\text { Amount of money (\$CAN) spent on alcohol during the past month, } \\
\text { mean and SD }\end{array}$ & $76 \cdot 10$ & $179 \cdot 28$ & $92 \cdot 71$ & $215 \cdot 05$ & 0.05 & $119 \cdot 16$ & $314 \cdot 81$ & 94.89 & $257 \cdot 85$ & 0.91 \\
\hline $\begin{array}{l}\text { Amount of money (\$CAN) spent on drugs during the past month, } \\
\text { mean and SD }\end{array}$ & $199 \cdot 27$ & $625 \cdot 58$ & $228 \cdot 26$ & $594 \cdot 41$ & 0.64 & $226 \cdot 88$ & $570 \cdot 25$ & $236 \cdot 45$ & $688 \cdot 72$ & 0.30 \\
\hline Percentage of money spent on alcohol, mean and SD & 14.8 & $28 \cdot 8$ & $15 \cdot 7$ & $28 \cdot 0$ & $0 \cdot 14$ & $15 \cdot 7$ & $29 \cdot 3$ & $14 \cdot 3$ & $27 \cdot 2$ & 0.97 \\
\hline Percentage of money spent on drugs, mean and SD & $20 \cdot 5$ & 33.7 & $20 \cdot 6$ & 33.5 & 0.84 & $23 \cdot 6$ & $34 \cdot 2$ & $19 \cdot 9$ & $31 \cdot 6$ & 0.08 \\
\hline \multicolumn{11}{|l|}{ Physical health } \\
\hline Úlcer (stomach or intestine) & 84 & $12 \cdot 2$ & 63 & $12 \cdot 4$ & 0.92 & 63 & 13.4 & 72 & $15 \cdot 0$ & 0.43 \\
\hline Bowel problems (Crohn's disease or colitis) & 67 & $9 \cdot 7$ & 51 & $10 \cdot 0$ & 0.87 & 47 & $10 \cdot 0$ & 53 & $11 \cdot 0$ & 0.59 \\
\hline High blood pressure & 153 & $22 \cdot 2$ & 102 & $20 \cdot 0$ & 0.32 & 99 & $21 \cdot 1$ & 98 & $20 \cdot 4$ & 0.89 \\
\hline Diabetes & 53 & $7 \cdot 7$ & 41 & $8 \cdot 1$ & 0.84 & 44 & 9.4 & 54 & $11 \cdot 2$ & 0.35 \\
\hline \multicolumn{11}{|l|}{ Service use } \\
\hline In past month, seen a health/social services provider at their office & 565 & 83.2 & 442 & 88.4 & 0.01 & 343 & $76 \cdot 4$ & 361 & $78 \cdot 3$ & 0.53 \\
\hline In the past 6 months, been to a hospital emergency room & 381 & $56 \cdot 1$ & 301 & $60 \cdot 7$ & 0.12 & 274 & 61.4 & 287 & $62 \cdot 7$ & 0.70 \\
\hline Baseline food security status & & & & & 0.24 & & & & & 0.85 \\
\hline Very low food security & 249 & $36 \cdot 7$ & 203 & $40 \cdot 4$ & & 203 & $45 \cdot 0$ & 209 & $45 \cdot 1$ & \\
\hline Low food security & 131 & $19 \cdot 3$ & 83 & $16 \cdot 5$ & & 72 & $16 \cdot 0$ & 83 & $17 \cdot 9$ & \\
\hline Marginal food security & 152 & $22 \cdots 4$ & 123 & 24.4 & & 97 & 21.5 & 95 & $20 \cdot 5$ & \\
\hline High food security & 148 & 21.8 & 94 & $18 \cdot 7$ & & 79 & $17 \cdot 5$ & 76 & $16 \cdot 4$ & \\
\hline
\end{tabular}

MN, moderate need; HN, high need; HF, Housing First; TAU, treatment as usual; MCAS, Multnomah Community Ability Scale; CSI, Colorado Symptom Index. 
There were no significant differences in baseline food security levels or any other baseline characteristics between the HF and TAU arms for the HN group.

In the MN group, a statistically significant association was observed between intervention arm and site $(P<0 \cdot 01)$. Moreover, a greater proportion of $\mathrm{MN}$ participants in the TAU arm saw a health or social services provider in the past month compared with those in the HF arm (88.4 v. 83.2\%; $P=0.01)$. Finally, TAU participants spent more money on alcohol in the past $30 \mathrm{~d}$ compared with HF participants (\$CAN $92.71 \quad(\mathrm{SD} 215.05) \quad v$. $\$$ CAN 76.10 (SD 179.28); $P=0 \cdot 05$ ).

\section{Multiple logistic regression results of predictors of baseline food security}

The results of the multiple logistic regression analyses are presented in Table 3. In the MN group, adjusted analyses revealed that the odds of reporting high or marginal food security status at baseline increased by $22 \%$ for each 10-year increment of age over 18 years (adjusted OR $(\mathrm{AOR})=1.22 ; 95 \%$ CI $1.04,1.42 ; P=0.02)$. Males compared with females were $32 \%$ less likely to report high or marginal food security status at baseline (AOR $=0 \cdot 68 ; 95 \%$ CI $0.48,0.97 ; P=0.03)$. Individuals experiencing higher (CSI score $\geq 30) v$. lower levels of mental health symptoms were $51 \%$ less likely to report high or marginal food security at baseline (AOR $=0.49 ; 95 \%$ CI $0.33,0.74$; $P<0 \cdot 01)$.

In the HN group, individuals reporting higher levels of psychiatric symptom severity were $56 \%$ less likely to report high or marginal food security status at baseline $(\mathrm{AOR}=0.44 ; 95 \% \mathrm{CI} 0.27,0.71 ; P<0.01)$. Moreover, among $\mathrm{HN}$ participants, for each $10 \%$ increase in the amount of income spent on drugs, participants were $16 \%$ less likely to report high or marginal food security status at baseline (AOR $=0 \cdot 84 ; 95 \%$ CI 0.77, 0.92; $P<0.01)$.

\section{Impact of Housing First on food security over the follow-up period}

A non-negligible number of participants did not complete the modified US FSSM during the 6-, 12-, 18- or 24-month follow-up visits, for whom we conservatively assigned values of 'food insecure' (low or very low food security). In total, of the $950 \mathrm{HN}$ participants, 202 were missing one report of the US FSSM, 109 were missing two data points and 159 were missing three or four US FSSM observations; for the MN group the numbers were 206, 103 and 157, respectively, out of a total of $1198 \mathrm{MN}$ participants. We found a statistically significant difference in age between those with and without missing US FSSM data, for both the $\mathrm{MN}(40.3 v .43 .3$ years) and the $\mathrm{HN}(38.6 v .40 \cdot 2$ years) group, respectively. No significant differences between those with and without missing US FSSM data were noted for gender, lifetime duration of homelessness, presence of health conditions such as ulcers or diabetes or high blood pressure, social service utilization and proportion of money spent on alcohol or drugs. In order to adjust for age differences between those with and without missing data, we included participant age as a covariate in the statistical models.

Over half of our sample was able to achieve high or marginal food security during the 18-month follow-up period and across our four trial arms between 35 and $38 \%$ never achieved high or marginal food security during follow-up (Fig. 2). The different arms ranged from 16 to $22 \%$ in the proportion of participants who achieved marginal to high food security three or more times over 18 months of follow-up.

Among the MN group, the negative binomial regression analyses showed no significant differences between the $\mathrm{HF}$ and TAU study arms with respect to the number of times high or marginal food security status was achieved over the 18-month follow-up period (Fig. 2). Moreover, the interaction between treatment arm and study site was not significant for the MN group.

Unlike the MN groups, there were statistically significant differences between treatment arms among $\mathrm{HN}$ participants. Overall, $61 \%$ of the HF arm compared with $54 \%$ of the TAU arm achieved marginal to high food security $(z=-2 \cdot 18, P=0 \cdot 02)$.

When examined by site, the HN treatment arms of Toronto and Moncton sites had higher rates of achieving high or marginal food security compared with the TAU groups over the 18-month study period (Fig. 3). The rate of achieving high or marginal food security for the HF arm compared with the TAU arm increased by a factor of 1.42 (95\% CI 1.04, 1.95; $P=0.03)$ for Moncton and $1.48(95 \%$ CI $1.11,1.97 ; P<0 \cdot 01)$ for Toronto.

\section{Discussion}

The present study is the first large-scale cross-site study to examine the prevalence of and factors associated with food security in a sample of individuals experiencing homelessness and mental illness. The prevalence of overall food security (high or marginal food security on US FSSM) observed in our study at baseline was higher than previously reported among homeless youth (8\%), lower than values reported by an earlier study of homeless adults in Toronto $(58 \%)^{(14)}$ and less than half the reported prevalence of high or marginal food security in the general population of Canada in $2012(90 \%)^{(9)}$. The results of the multiple logistic regression analyses suggest that in the absence of an intervention the level of food security at baseline was associated with a few individual-level factors: being male and young. These findings are in line with prior studies demonstrating that food security is associated with demographic variables such as gender and young age $^{(13,44)}$. Consistent with our findings, prior research has also identified increased food insecurity among individuals experiencing homelessness who face additional 
Table 3 Unadjusted and adjusted odds ratios for variables associated with high or marginal food security status at baseline* among At Home/Chez Soi study participants for all five sites by need level. Participants were individuals ( $n$ 2148) experiencing homelessness and mental illness enrolled at five Canadian sites (Moncton, Montreal, Toronto, Winnipeg and Vancouver), October 2009 to July 2011

\begin{tabular}{|c|c|c|c|c|c|c|c|c|c|c|c|c|}
\hline \multirow[b]{2}{*}{ Variable } & \multicolumn{6}{|c|}{$\mathrm{MN}(n 715)$} & \multicolumn{6}{|c|}{$\mathrm{HN}(n 535)$} \\
\hline & UOR & $95 \% \mathrm{Cl}$ & $P$ & AOR & $95 \% \mathrm{Cl}$ & $P$ & UOR & $95 \% \mathrm{Cl}$ & $P$ & AOR & $95 \% \mathrm{Cl}$ & $P$ \\
\hline \multicolumn{13}{|l|}{ Demographic variables } \\
\hline Age at baseline† & 1.23 & $1.11,1.36$ & $<0.01$ & 1.22 & $1.04,1.42$ & 0.02 & 1.02 & $0.90,1.15$ & 0.74 & 0.84 & $0.69,1.02$ & 0.07 \\
\hline Male & 0.71 & $0.55,0.90$ & $<0.01$ & 0.68 & $0.48,0.97$ & 0.03 & $1 \cdot 13$ & $0.85,1.51$ & 0.39 & 1.37 & $0 \cdot 86,2 \cdot 16$ & 0.18 \\
\hline \multicolumn{13}{|l|}{ Homelessness variable } \\
\hline Homelessness duration $\geq 3$ years & 0.66 & $0.52,0.84$ & $<0.01$ & 0.86 & $0.62,1.18$ & 0.34 & 0.99 & $0.76,1.31$ & 0.98 & 1.04 & $0.68,1.60$ & 0.85 \\
\hline \multicolumn{13}{|l|}{ Community functioning variable } \\
\hline MCAS total score $\ddagger$ & $1 \cdot 12$ & $1.02,1.24$ & 0.02 & 1.07 & $0.93,1.24$ & 0.37 & 0.88 & $0.80,0.97$ & 0.01 & 1.01 & $0.85,1.19$ & 0.93 \\
\hline \multicolumn{13}{|l|}{ Mental health and substance use variables } \\
\hline CSI total score $\geq 30$ & 0.41 & $0.30,0.56$ & $<0.01$ & 0.49 & $0.33,0.74$ & $<0.01$ & 0.35 & $0.24,0.49$ & $<0.01$ & 0.44 & $0.27,0.71$ & $<0.01$ \\
\hline Days in the past month experienced alcohol problems & 0.96 & $0.95,0.98$ & $<0.01$ & 0.99 & $0.97,1.01$ & 0.43 & 0.98 & $0.96,0.99$ & 0.02 & 0.99 & $0.97,1.02$ & 0.64 \\
\hline Days in the past month experienced drug problems & 0.97 & $0.96,0.98$ & $<0.01$ & 0.98 & $0.97,1.00$ & $0 \cdot 10$ & 0.97 & $0.95,0.98$ & $<0.01$ & 1.00 & $0.98,1.02$ & 0.81 \\
\hline Percentage of income spent on alcohol $\dagger$ & 0.90 & $0.86,0.94$ & $<0.01$ & 0.99 & $0.92,1.06$ & 0.75 & 0.94 & $0.89,0.99$ & 0.03 & 0.97 & $0.88,1.06$ & 0.44 \\
\hline Percentage of income spent on drugst & 0.93 & $0.89,0.97$ & $<0.01$ & 0.96 & $0.90,1.02$ & 0.18 & 0.86 & $0.82,0.91$ & $<0.01$ & 0.84 & $0.77,0.92$ & $<0.01$ \\
\hline \multicolumn{13}{|l|}{ Physical health variables } \\
\hline Úlcer (stomach or intestine) & 0.55 & $0.38,0.79$ & $<0.01$ & 0.69 & $0.41,1 \cdot 16$ & $0 \cdot 16$ & 0.56 & $0.37,0.85$ & $<0.01$ & 0.75 & $0.40,1.38$ & 0.35 \\
\hline Bowel problems (Crohn's disease or colitis) & 0.85 & $0.58,1.25$ & 0.41 & 1.50 & $0.88,2.57$ & 0.14 & 0.73 & $0.47,1.14$ & 0.17 & 0.93 & $0.45,1.89$ & 0.83 \\
\hline High blood pressure & 1.12 & $0.84,1.48$ & 0.43 & 1.23 & $0.83,1.82$ & 0.30 & 0.65 & $0.47,0.92$ & 0.01 & 0.88 & $0.51,1.52$ & 0.65 \\
\hline Diabetes & 1.03 & $0.67,1.57$ & 0.90 & 0.56 & $0.30,1.07$ & 0.08 & 0.74 & $0.47,1.17$ & 0.20 & 0.72 & $0.35,1.50$ & 0.38 \\
\hline \multicolumn{13}{|l|}{ Service variables } \\
\hline Seen health/social services provider in past month & 0.93 & $0.67,1.28$ & 0.65 & 1.05 & $0.64,1.72$ & 0.85 & 0.77 & $0.56,1.05$ & $0 \cdot 10$ & 1.25 & $0.77,2.05$ & 0.37 \\
\hline Any emergency room visits in the past 6 months & 0.79 & $0.63,1.00$ & 0.05 & 0.80 & $0.58,1.11$ & 0.18 & 0.78 & $0.59,1.03$ & 0.08 & 0.71 & $0.47,1.07$ & 0.10 \\
\hline
\end{tabular}

MN, moderate need; HN, high need; UOR, unadjusted odds ratio; AOR, adjusted odds ratio; MCAS, Multnomah Community Ability Scale; CSI, Colorado Symptom Index.

${ }^{*}$ The analysis was also adjusted for site (data not shown).

TOR in 10.0 units.

¥OR in $5 \cdot 0$ units. 


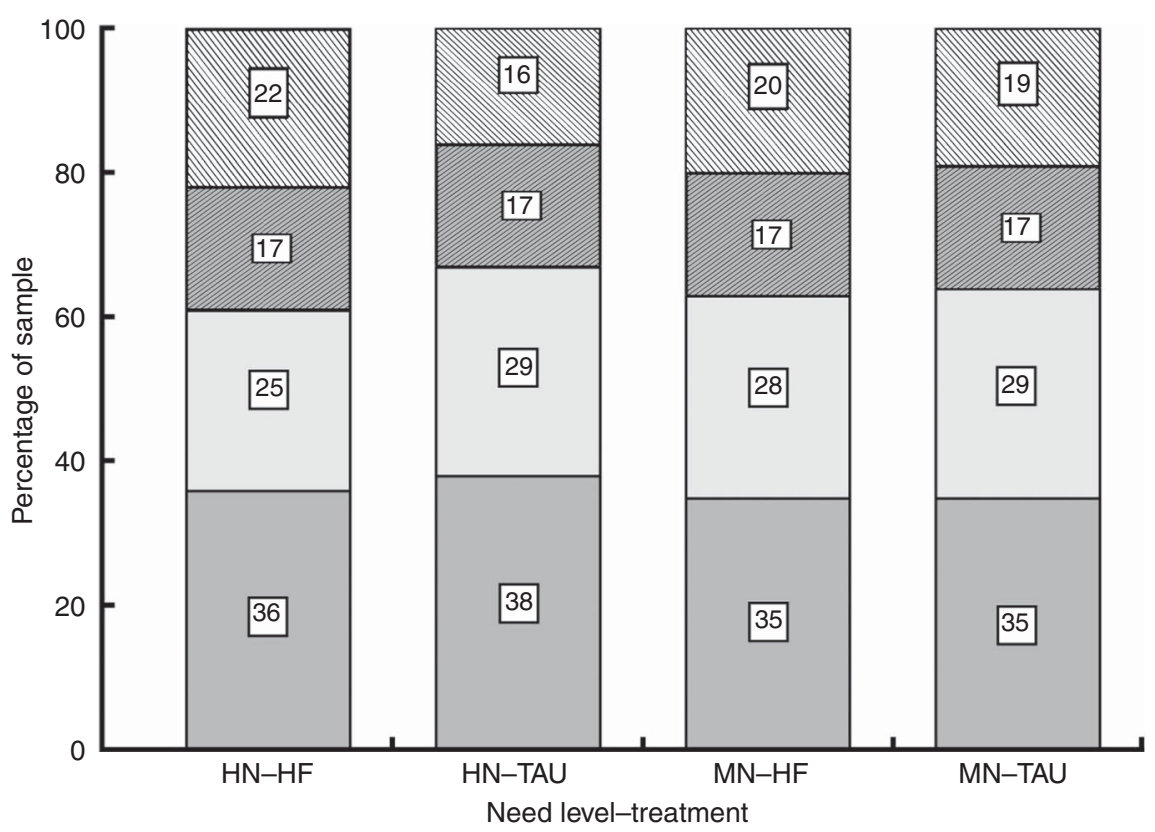

Fig. 2 Percentage of the sample of At Home/Chez Soi study participants who achieved high or marginal food security a given number of times over the 18-month follow-up period ( $\square$, zero times; $\square$, one time;, two times; $\square$, three or more times), by need level (HN, high need; MN, moderate need) and randomization group (HF, Home First; TAU, treatment as usual). Participants were individuals ( $n$ 2148) experiencing homelessness and mental illness enrolled at five Canadian sites (Moncton, Montreal, Toronto, Winnipeg and Vancouver), October 2009 to July 2011

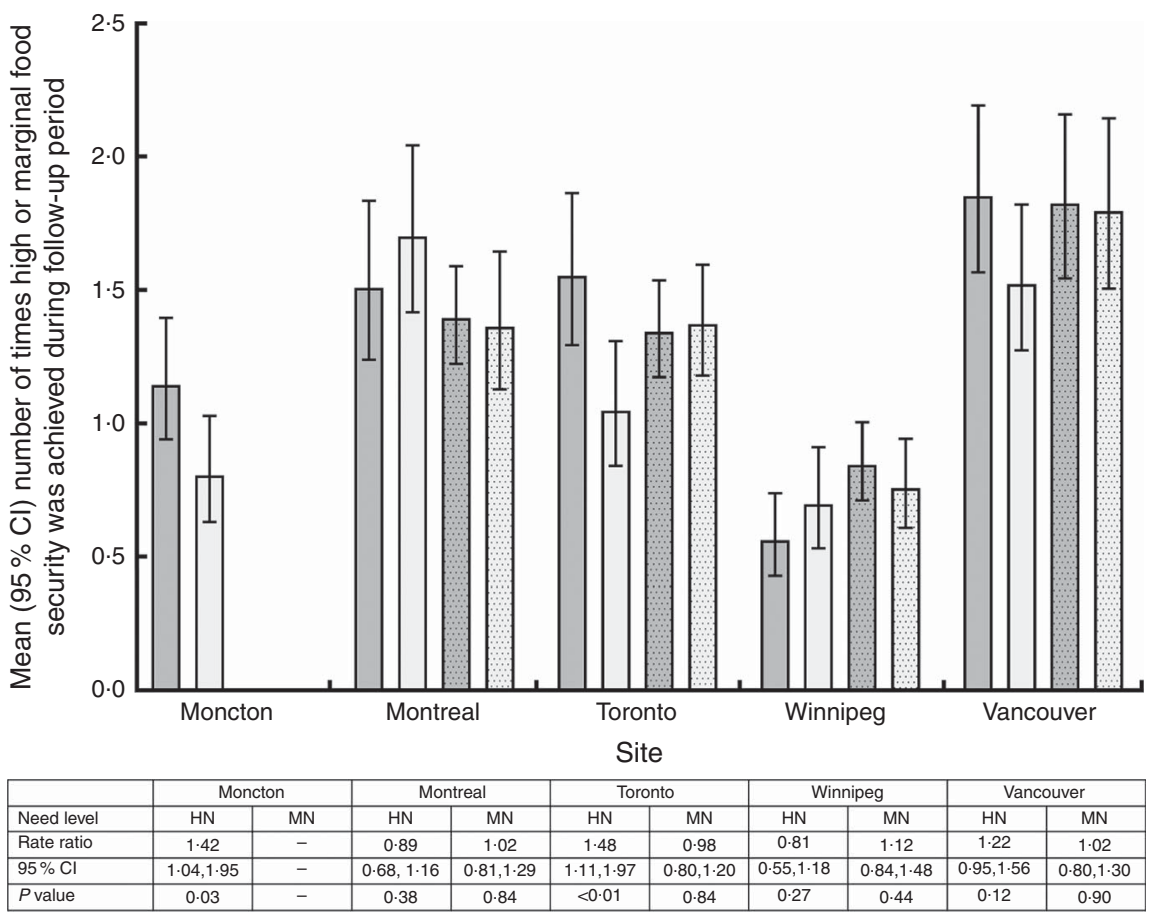

Fig. 3 Mean (with $95 \% \mathrm{Cl}$ represented by vertical bars) number of times At Home/Chez Soi study participants achieved high or marginal food security over the 18-month follow-up period, by study site and randomization group ( $\square$, HN-HF; $\square$, HN-TAU; 圈, MN-HF; 圈, MN-TAU). The table below shows rate ratios $(95 \% \mathrm{Cl})$ for the Home First (HF) group compared with the treatment as usual (TAU) group, at each site, by need level (HN, high need; MN, moderate need). Participants were individuals ( $n$ 2148) experiencing homelessness and mental illness enrolled at five Canadian sites (Moncton, Montreal, Toronto, Winnipeg and Vancouver), October 2009 to July 2011 
obstacles, such as alcohol or substance use problems. Studies have suggested that individuals with dependence or addiction problems may have impaired decision making about how they spend their money ${ }^{(13)}$; however, others have failed to confirm this association ${ }^{(18)}$. In contrast with previous research ${ }^{(13,18)}$, we did not observe an association between food security and lifetime duration of homelessness of 3 years or longer. However, it is possible that this cut-off may have been too short for older adults who may have been on the street for many years. These discrepant findings may further be due to differences in the composition of populations studied (compared with other studies, the participants in the current study were all experiencing both homeless and mental illness) ${ }^{(13)}$, use of different measures of food security and use of different predictors in analyses ${ }^{(13,18)}$. Neither physical health variables, community functioning nor health-service use variables were associated with food security in our sample. Further longitudinal studies such as ours are needed to clarify the association between these factors and food security among individuals experiencing homelessness. Taken together, our findings contribute to a growing body of literature indicating the difficulties of achieving food security among individuals experiencing homelessness.

To our knowledge, ours is the first study to examine the impact of a supported housing intervention on food security in a sample of participants experiencing homelessness and mental illness. We hypothesized that access to housing would improve food security among HF participants by providing them with access to kitchen facilities where they can prepare and store food. Taking advantage of the longitudinal nature of our data, we documented that over half of our sample was able to achieve marginal to high food security at least one time over the 18-month period. Moreover, about one-fifth of participants in both treatment arms achieved moderate to high food security throughout the follow-up period. Interestingly, only within the HN group did those in the HF arm show greater improvements in food security over the 18 months of follow-up compared with those in the TAU arm.

Our findings show that the rate of achieving high or marginal food security was higher in the HF group compared with the TAU group in only two of the five study sites that had an HN group (Moncton and Toronto). This is not surprising given that each site had unique contexts and populations. For example, in Winnipeg, the majority of participants were of Aboriginal background and in Toronto the sample comprised a large proportion of ethno-racial and non-Canadian-born participants. There are several additional reasons for variation in intervention effects across sites. Although all study sites achieved high levels of fidelity to the HF programme model ${ }^{(45)}$, variation may have existed in the implementation of the HF intervention and it is likely that the ability of support teams to refer clients to services related to food security was not uniform.
Site differences may also have arisen from heterogeneity in the composition of the homeless population and food landscapes in each community, including availability of affordable or accessible healthy food options. Moreover, participants in the TAU arms were not precluded from obtaining housing throughout the study period and some were successfully housed via existing programmes and services; however, HF participants in both need level groups were able to achieve greater housing stability compared with their TAU counterparts ${ }^{(33,46)}$.

It is also unclear to what extent our results are driven by other factors related to food security that were not assessed in our study such as household size, proximity to relevant resources and expenditures ${ }^{(19,47)}$. HF was unable to and did not seek to fully alleviate poverty, which may be an additional explanation for our findings. Social protection programmes, which include social assistance, social insurance and labour market protection, may be better equipped to address the multidimensional factors surrounding poverty and deprivation and may have a more tangible effect on food security in this population ${ }^{(48)}$. Moreover, it is also plausible that the HF intervention may not directly influence food security. In our sample, regardless of the treatment arm, over half of the participants achieved a high food security level at least once during the four follow-up visits. It is also important to note, however, that the US FSSM only captures food security arising from economic constraints ${ }^{(2,40,41)}$, and we are therefore unable to comment on whether the HF intervention was able to improve the physical and social domains of our participants' food security. Further research is required to examine how these and other factors impact and improve food security.

Although our study has notable strengths (e.g. large sample size, longitudinal follow-up, diverse study sites, use of a validated food security measure), it also had the following limitations. Recall bias may have influenced the accuracy of participants' self-reported data. Because participants received an honorarium for their participation, we cannot dismiss that this incentive may have also biased their answers. Given that all participants had to be experiencing severe mental illness with or without a concurrent substance use problem in order to be eligible for the study, our findings may not be generalizable to the entire homeless population. Blinding of interviewers and participants to their randomization was not possible due to the nature of the intervention and may have also resulted in biased estimates of treatment effects ${ }^{(49)}$.

In summary, food security was low among individuals experiencing homelessness and mental illness in the At Home/Chez Soi study and was associated with demographic variables and mental health and substance use problems. Although few participants achieved food security throughout the follow-up period, our findings suggest that an HF intervention does result in higher rates of food security compared with usual care over an 
18-month study period, especially among HN individuals. Differences in the treatment effect across study sites indicate that variation between cities in terms of study population characteristics and food landscapes may play a factor. Food security continues to be a significant issue in Canada that requires coordinated and effective policies and programmes to ensure that homeless individuals with severe mental illness have adequate access to food assistances programmes and income for food.

\section{Acknowledgements}

Acknowledgements: The authors would like to thank the following for their contribution to this project and the research: Dr Jayne Barker (2008-2011), Cameron Keller (2011-2012) and Catharine Hume (2012-present), Mental Health Commission of Canada At Home/Chez Soi National Project Leads; Dr Paula Goering, the National Research Lead; the National Research Team, the five site research teams, the Site Coordinators, and the numerous service and housing providers; as well as the persons with lived experience. Financial support: This research was supported by the Mental Health Commission of Canada, via funds from Health Canada. The views expressed herein solely represent the authors. Conflict of interest: None. Authorship: P.O. and S.W.H. designed the study. All authors contributed to the formulation of the research questions, study design and interpretation of the empirical results. P.O., S.W.H., A.S., A.G. and L.I.P.L. planned the statistical analysis. L.I.P.L. performed all statistical analyses. P.O., A.S. and A.G. wrote the original draft and all authors provided comments and corrections on manuscript versions. All authors read and approved the final manuscript draft. Ethics of buman subject participation: This study was conducted according to the guidelines laid down in the Declaration of Helsinki and all procedures involving human subjects were approved by the institutional research ethics boards (REB) at each study site (University of Moncton REB in Moncton; Douglas Mental Health University Institute REB in Montreal; St. Michael's Hospital REB in Toronto; University of Winnipeg REB in Winnipeg; Simon Fraser University REB in Vancouver). All participants received information on the study and provided their written informed consent. Trial registration: The study was registered with the International Standard Randomized Control Trial Number (ISRCTN) 42520374 on 18 August 2009.

\section{References}

1. Tarasuk V (2005) Household food insecurity in Canada. Top Clin Nutr 20, 299-312.

2. Food and Agriculture Organization of the United Nations (1996) Rome Declaration on World Food Security. http:// www.fao.org/docrep/003/w3613e/w3613e00.HTM (accessed July 2016).

3. Anema A, Vogenthaler N, Frongillo EA et al. (2009) Food insecurity and HIV/AIDS: current knowledge, gaps, and research priorities. Curr HIV/AIDS Rep 6, 224-231.
4. Cook JT, Frank DA, Berkowitz C et al. (2004) Food insecurity is associated with adverse health outcomes among human infants and toddlers. J Nutr 134, 1432-1438.

5. Ramsey R, Giskes K, Turrell G et al. (2012) Food insecurity among adults residing in disadvantaged urban areas: potential health and dietary consequences. Public Health Nutr 15, 227-237.

6. Seligman HK, Laraia BA \& Kushel MB (2010) Food insecurity is associated with chronic disease among low-income NHANES participants. J Nutr 140, 304-310.

7. Tarasuk V, Dachner N, Hamelin AM et al. (2014) A survey of food bank operations in five Canadian cities. BMC Public Health 14, 1234.

8. Coleman-Jensen A, Gregory C \& Singh A (2014) Household Food Security in the United States in 2013. Economic Research Report no. ERR-173. Washington, DC: US Department of Agriculture, Economic Research Service.

9. Tarasuk V, Mitchell A \& Dachner N (2014) Household Food Insecurity in Canada, 2012. Toronto: Research to identify policy options to reduce food insecurity (PROOF); available at http://proof.utoronto.ca/wp-content/uploads/2014/05/ Household_Food_Insecurity_in_Canada-2012_ENG.pdf.

10. Gorton D, Bullen CR \& Mhurchu CN (2010) Environmental influences on food security in high-income countries. Nutr Rev 68, 1-29.

11. McIntyre L, Bartoo AC, Pow J et al. (2012) Coping with child hunger in Canada: have household strategies changed over a decade? Can J Public Health 103, e428-e432.

12. Office of Nutrition Policy and Promotion, Health Products and Food Branch (2007) Income-related Household Food Security in Canada. Catalogue no. H164-42/2007E. Ottawa: Health Canada.

13. Lee BA \& Greif MJ (2008) Homelessness and hunger. $J$ Health Soc Behav 49, 3-19.

14. Holland AC, Kennedy MC \& Hwang SW (2011) The assessment of food security in homeless individuals: a comparison of the Food Security Survey Module and the Household Food Insecurity Access Scale. Public Health Nutr 14, 2254-2259.

15. Li A, Dachner N \& Tarasuk V (2009) Food intake patterns of homeless youth in Toronto. Can J Public Health 100, 36-40.

16. Tarasuk V, Dachner N \& Li J (2005) Homeless youth in Toronto are nutritionally vulnerable. J Nutr $\mathbf{1 3 5}$, 1926-1933.

17. Tarasuk V, Dachner N, Poland B et al. (2009) Food deprivation is integral to the 'hand to mouth' existence of homeless youths in Toronto. Public Health Nutr 12, 14371442.

18. Baggett TP, Singer DE, Rao SR et al. (2011) Food insufficiency and health services utilization in a national sample of homeless adults. J Gen Intern Med 26, 627-634.

19. Weiser SD, Frongillo EA, Ragland $\mathrm{K}$ et al. (2009) Food insecurity is associated with incomplete HIV RNA suppression among homeless and marginally housed HIVinfected individuals in San Francisco. J Gen Intern Med 24, 14-20.

20. Richards R \& Smith C (2006) The impact of homeless shelters on food access and choice among homeless families in Minnesota. J Nutr Educ Behav 38, 96-105.

21. Wicks R, Trevena LJ \& Quine S (2006) Experiences of food insecurity among urban soup kitchen consumers: insights for improving nutrition and well-being. J Am Diet Assoc 106, 921-924.

22. Goetz J (2008) Exploring food insecurity among individuals with serious mental illness: a qualitative study. PhD Thesis, University of Kansas.

23. Mangurian C, Sreshta N \& Seligman H (2013) Food insecurity among adults with severe mental illness. Psychiatr Serv 64, 931-932. 
24. Muldoon KA, Duff PK, Fielden S et al. (2013) Food insufficiency is associated with psychiatric morbidity in a nationally representative study of mental illness among food insecure Canadians. Soc Psychiatry Psychiatr Epidemiol 48, 795-803.

25. Kirkpatrick SI \& Tarasuk V (2009) Food insecurity and participation in community food programs among low-income Toronto families. Can J Public Health 100, 135-139.

26. Roncarolo F, Adam C, Bisset S et al. (2015) Traditional and alternative community food security interventions in Montreal, Quebec: different practices, different people. J Community Health 40, 199-207.

27. Armstrong D (2000) A survey of community gardens in upstate New York: implications for health promotion and community development. Health Place 6, 319-327.

28. Engler-Stringer R \& Berenbaum S (2005) Collective kitchens in Canada: a review of the literature. Can J Diet Pract Res 66, 246-251.

29. Loopstra R \& Tarasuk V (2012) The relationship between food banks and household food insecurity among lowincome Toronto families. Can Public Policy 38, 497-514.

30. Vozoris NT \& Tarasuk VS (2003) Household food insufficiency is associated with poorer health. J Nutr 133, 120-126.

31. Aubry T, Tsemberis S, Adair CE et al. (2015) One-year outcomes of a randomized controlled trial of housing first with ACT in five Canadian cities. Psychiatr Serv $\mathbf{6 6}$, 463-469.

32. Padgett DK, Stanhope V, Henwood BF et al. (2011) Substance use outcomes among homeless clients with serious mental illness: comparing Housing First with Treatment First programs. Community Ment Health J 47, 227-232.

33. Stergiopoulos V, Hwang SW, Gozdzik A et al. (2015) Effect of scattered-site housing using rent supplements and intensive case management on housing stability among homeless adults with mental illness: a randomized trial. JAMA 313, 905-915.

34. Tsai J, Mares AS \& Rosenheck RA (2010) A multi-site comparison of supported housing for chronically homeless adults: 'housing first' versus 'residential treatment first'. Psychol Serv 7, 219-232.

35. Tsemberis S, Gulcur L \& Nakae M (2004) Housing First, consumer choice, and harm reduction for homeless individuals with a dual diagnosis. Am J Public Health 94 651-656.

36. Goering PN, Streiner DL, Adair C et al. (2011) The At Home/ Chez Soi trial protocol: a pragmatic, multi-site, randomised controlled trial of a Housing First intervention for homeless individuals with mental illness in five Canadian cities. BMJ Open 1, e000323.

37. Barker S, Barron N, McFarland BH et al. (1994) A community ability scale for chronically mentally ill consumers: Part II. Applications. Community Ment Health J 30, 459-472.

38. Sheehan DV, Lecrubier Y, Sheehan KH et al. (1998) The Mini-International Neuropsychiatric Interview (MINI): the development and validation of a structured diagnostic psychiatric interview for DSM-IV and ICD-10. J Clin Psychiatry 59, Suppl. 20, 22-33.

39. Bickel G, Nord M, Price C et al. (2000) Guide to Measuring Housebold Food Security, Revised 2000. Alexandria, VA: US Department of Agriculture, Food and Nutrition Service.

40. Food and Agriculture Organization of the United Nations (2008) An Introduction to the Basic Concepts of Food Security. Rome: FAO; available at http://www.fao.org/ docrep/013/al936e/al936e00.pdf

41. United States Department of Agriculture Economic Reserach Service (2015) Definitions of food security. http://www. ers.usda.gov/topics/food-nutrition-assistance/food-security-inthe-us/definitions-of-food-security.aspx (accessed July 2016).

42. Boothroyd R \& Chen H (2008) The psychometric properties of the Colorado Symptom Index. Adm Policy Ment Health 35, 370-378.

43. Streiner DL \& Norman GR (2011) Correction for multiple testing: is there a resolution? Chest 140, 16-18.

44. Hamelin AM \& Hamel D (2009) Food insufficiency in currently or formerly homeless persons is associated with poorer health. Can J Urban Res 18, 1-24.

45. Nelson G, Stefancic A, Rae J et al. (2014) Early implementation evaluation of a multi-site housing first intervention for homeless people with mental illness: a mixed methods approach. Eval Program Plann 43, 16-26.

46. Aubry T, Goering P, Veldhuizen S et al. (2016) A multiplecity RCT of housing first with assertive community treatment for homeless Canadians with serious mental illness. Psychiatr Serv 67, 275-281.

47. Furness BW, Simon PA, Wold CM et al. (2004) Prevalence and predictors of food insecurity among low-income households in Los Angeles County. Public Health Nutr 7, 791-794.

48. Food and Agriculature Organization of the United Nations (2015) The State of Food and Agriculture 2015. Social Protection and Agriculture: Breaking the Cycle of Rural Poverty. Rome: FAO; available at http://www.fao.org/3/ a-i4910e.pdf

49. Karanicolas PJ, Farrokhyar F \& Bhandari M (2010) Practical tips for surgical research: blinding: who, what, when, why, how? Can J Surg 53, 345-348. 